\title{
A MACROECONOMIC ANALYSIS OF PUBLICLY FUNDED HEALTH CARE*
}

Heather L. Bednarek

Center for Cost and Financing Studies

Agency for Healthcare Research and Quality

2101 E. Jefferson St. Suite 500

Rockville, MD 20852

hbednare@ahrq.gov
Rowena A. Pecchenino

Department of Economics

Michigan State University

101 Marshall Hall

East Lansing, MI 48824

rowenap@msu.edu

*This work was primarily done while Bednarek was affiliated with the Department of Economics, Michigan State University. The views expressed in this paper are those of the authors and no official endorsement by the Agency for Healthcare Research and Quality or the Department of Health and Human Services is intended or should be inferred. The authors would like to thank two anonymous referees, the participants of the 1999 SITE conference at Stanford University, Barbara Schone, seminar participants at Michigan State University and the Economic and Social Research Institute, Dublin, Ireland for helpful comments. 


\section{A MACROECONOMIC ANALYSIS OF PUBLICLY FU}

Heather Bednarek

Center for Cost and Financing Studies

Agency for Healthcare Research and Quality

2101 E. Jefferson St., Suite 500

Rockville, MD 20852

Phone: (301)594-2841

Email: hbednare@ahrq.gov

In a general equilibrium, overlapping generations framework this paper examines how the tax-benefit system that underlies the US health care system affects the well-being of different age groups, and the lifetime well-being of different socio-economic groups, as well as society as a whole. We find that the optimal set and generosity of publicly funded health care programs is sensitive to the social welfare function and to the prices that various agents in society pay for medical care. Social welfare under the current financing system is also compared to alternative financing mechanisms such as Medical Savings Accounts.

JEL Classifications: H51, I18 


\section{Introduction}

Election years tend to focus attention on government policies past and future. The 2000 election year was no different, and both candidates Bush and Gore proposed changes to Medicare and/or Medicaid. ${ }^{1}$ While these proposals were designed to attract votes, a more careful, dispassionate examination of the government's role in the US health care system is needed prior to the enactment of policy changes which may benefit a key constituency today but may hurt society as a whole in the more distant future.

There are three major government health care programs: Medicare, Medicaid, and tax benefits for employer provided health benefits. Medicare, the government subsidized health care program primarily for the elderly, has great popular appeal. In its first 35 years it has had great success in achieving its goal: a more healthy population of elderly who enjoy retirement with little fear of being driven into destitution by ill health. Medicaid is means-tested and subsidizes health care for low-income individuals. It helps finance long-term care for the elderly after they have depleted their income and assets, although it was initially designed with the health care of low-income families, the blind and the disabled in mind. ${ }^{2}$ Finally, employer provided health care benefits are not taxed, giving workers the ability to "buy" health care out of before-tax rather than after-tax dollars.

In this paper we are interested in determining how the tax-benefit system that underlies the US health care system affects the well-being of different age groups, and the lifetime well-

\footnotetext{
${ }^{1}$ The Bush and Gore proposals were similar to the competing proposals discussed in Congress. See McClellan (2000), Cutler (2000), Fuchs (2000), Reinhardt (2000) and Saving (2000) for a discussion of Medicare reform. ${ }^{2}$ An important distinction should be noted regarding references to Medicaid in this paper. Due to new legislation and initiatives by various states, several spin-off programs have developed out of what has traditionally been called Medicaid. Throughout the paper we refer to Medicaid in a rather broad sense, encompassing both traditional Medicaid as well as the new programs that are outgrowths.
} 
being of different socio-economic groups, as well as society as a whole. That is, we are interested in the broad social goals implicit in these health care programs. This research is prompted in part by the finding that Medicare redistributes wealth from the poor to the rich (McClellan and Skinner, 1997), which indicates that social welfare may be harmed by the program. At the same time we observe the out-of-hand rejection by the Clinton Administration of the proposal by the National Bipartisan Commission on the Future of Medicare to means-test some benefits provided by Medicare (Economist, 1999), a clear attempt to improve the equitable distribution of benefits should such means testing not undermine support for the Medicare program. Further, while taxes to fund Medicare are currently low, and so the effects on those paying them may be small, projections of program growth imply substantial tax hikes (Feldstein, 1999), so substantial that the effects on the well-being of the taxpayers, the future Medicare beneficiaries, cannot realistically be ignored.

To examine the various social and individual welfare effects of the inter- and intragenerational redistributions that result from the existing health care tax-benefit system we develop an overlapping generations model in which agents differ in age, income/wealth and health status. In our model agents' lifetime choices are affected both by the benefits they receive and the taxes they pay whether they receive benefits or not. Thus, our model, because of its general equilibrium nature, allows us to analyze both the direct and indirect effects of all programs simultaneously on social welfare rather than on the welfare of a specific target group.

We find that optimal subsidies for Medicare and Medicaid are sensitive to the social welfare function (i.e. relative weights on young vs. old, rich vs. poor in the economy), prices that various agents in society pay for medical care, and to a lesser extent, income disparity. For example, the optimal Medicare subsidy rate is often zero for parameterizations of the model 
where the young and old have equal weight. However, if the old have greater weight in the social welfare function we observe positive optimal Medicare subsidy rates. Alternatively, suppose Medicare exists because of adverse selection in the market for health insurance for the elderly. If the costs of adverse selection are relatively low so that the government's policies can effect only small price reductions relative to the private market, then society is better off with a smaller or no Medicare subsidy. Positive Medicaid subsidies for the poor young are optimal only when the poor young have at least equal weight relative to the rich young. As the government administered price of medical care decreases relative to the market price, the optimal Medicaid subsidy rate increases. When the programs are social welfare enhancing, they are also redistributive from the rich to the poor both intra- and intergenerationally, where the optimal degree of redistribution increases as the income distribution becomes more unequal. This is true when the programs subsidize medical care at a uniform rate as well as when the subsidy rate is income dependent. In the latter case, the optimal programs are means-tested. Social welfare under the alternative financing mechanisms of Medical Savings Accounts and a forced medical saving program are also examined relative to the current financing system.

The paper proceeds as follows. Section 2 first presents the key features of the Medicare and Medicaid programs, and describes how program details are summarized in our model. Section 2 concludes with a review of the literature, which has mainly focused on individual programs rather than on how these programs interact and affect individuals' lifetime well-being. The model is then set out in Section 3. The equilibrium is defined in Section 4. In Section 5 the parameterization of the model is outlined and the social welfare properties of the programs are derived and discussed. Section 6 examines alternative health care financing mechanisms and conclusions are drawn in Section 7. 


\section{Background}

\subsection{Public Health Care Programs}

Medicare

Medicare is the centerpiece of the government health care programs. Two years ago it was thought to be on the brink of collapse, however under current budget projections it will be 2023 before it is unable to fund benefits out of current tax receipts. The prediction of "bankruptcy" led to the creation of the National Bipartisan Commission on the Future of Medicare (1998-99) to study the problem and make recommendations. But, the commission members could not agree on a single reform plan, and so their work was shelved. The commission's work was instrumental in generating the three competing plans that are currently under consideration, but no action is expected soon.

Medicare is public health insurance for virtually all those 65 and over. It consists of two components. Part A, Hospital Insurance (HI), covers inpatient hospital care, some skilled nursing facility care, most home health care, and hospice care. Participation in this part of Medicare is compulsory and is generally premium free, although there is a deductible of almost $\$ 800$ per year as well as co-insurance rates for hospital stays that exceed 60 days. Part A is funded by a payroll tax of $1.45 \%$ on both the worker and employer, for a total of $2.9 \%$ on all earnings. Part B, Supplementary Medical Insurance (SMI), primarily covers physician services, out-patient procedures, some home health care and laboratory tests. Part B pays approximately $80 \%$ of the costs for physician and out-patient procedures and is optional though most individuals enroll. Those enrolled must pay $20 \%$ of most care as well as a monthly premium of $\$ 50$ and a $\$ 100$ yearly deductible for the Part B 80\% coverage. These monthly premiums cover approximately $25 \%$ of Part B total costs while general revenues finance the remaining $75 \%$. 
Medicare does not employ a single uniform pricing policy but instead uses a complex system of administered prices. Inpatient care (Part A) is primarily paid for using flat fees that vary by diagnosis. Physician services (Part B) are primarily paid for on a fee for service basis. The fees are based on the relative resource effort of the physicians providing the service, adjusted for factors such as specialty and local input prices. Since we employ a macroeconomic framework we attempt to capture some of the overriding themes of Medicare. Thus, we abstract from distinctions between Part A and Part B in terms of the differences in pricing policy.

To better understand our model in section 3, we discuss the way in which we interpret the rate at which the government subsidizes care as being distinct from the government affecting medical care prices. Because individuals are required to pay premiums and deductibles, Medicare does not pay $100 \%$ of the medical care that these individuals receive. Instead it pays some percentage of the entire cost and that is what we refer to as the Medicare subsidy rate, $\sigma$. Individuals can choose to finance the portion of expenditures the government does not subsidize out-of-pocket, via a Medigap policy or an employer provided/retiree supplemental policy. We do not explicitly model the latter two possibilities. Second, when we consider the government's ability to affect or negotiate medical care prices we interpret this as separate from the subsidy rate. The government bargains over rules for setting prices or "reasonable" payments for daily hospital costs and procedures. We refer to this as the government's administered price of medical care, $g$, for the subsidized portion $(\sigma)$ of medical care which may be different from the price that individuals face, $p$, for the unsubsidized portion $(1-\sigma)$. Anything which lowers the price of the government's share of medical care, $g$, or any increase in the direct subsidy rate, $\sigma$, is likely to have distortionary effects via increasing the demand for medical goods above what individuals would demand without Medicare. 


\section{Medicaid}

Medicaid provides medical benefits to certain vulnerable groups of low-income individuals. While Medicaid helps finance long-term care for the elderly, our focus is on the health care of low-income working age individuals for whom it was specifically designed. This program is jointly financed by both the federal and state governments via general revenues. The federal government has guidelines that states must follow in order to receive federal grants, but the program is administered at the state level, thus eligibility standards, scope of services and rates of payment vary from state to state. States are required to cover "categorically needy" groups such as individuals who were eligible for Medicaid via the Aid to Families with Dependent Children link prior to the July 16, 1996 enactment of Welfare-to-Work legislation, income eligible Medicare beneficiaries and other specially protected groups. States have the option of defining eligibility criteria more liberally and covering "categorically related" groups for which they will still receive federal matching funds.

All states' Medicaid programs must cover certain basic services. States may choose to pay providers directly for services or indirectly via a health maintenance organization (HMO). They may also impose nominal deductibles, coinsurance or co-payments on some Medicaid recipients. States can also apply for permission (1115 waiver) to implement statewide reforms to test various methods for covering uninsured populations and new delivery systems without increasing costs. In 1998, 15 states had received such a waiver and several more were under review. The states that have been granted waivers have substantially overhauled their systems. ${ }^{3}$

\footnotetext{
${ }^{3}$ For more detailed information on the changes various states such as Hawaii, Tennessee and Wisconsin are undertaking see, for example, HCFA Health Reform Demonstration Fact Sheets (1998) and Ellwood (1999).
} 
While states' reforms are of varying degrees, in most cases efforts are being made to provide subsidies to low-income individuals, some of whom may have some labor force attachment. In the macroeconomic framework of this paper we must make some generalizing assumptions about who qualifies for Medicaid and cannot model the specifics of special group eligibility as well as generalize to a single government entity without making federal and state level distinctions. Given the broad changes that various states are making, we choose to model Medicaid for workers simply as a subsidy, $\eta$, where the government pays a portion $(\eta)$ of individuals' medical care. This captures the notion that low-income individuals gain access to medical benefits via public group insurance rather than strictly via out-of-pocket payment or nongroup insurance coverage. As with Medicare we allow for the government's ability to bargain for medical care prices, $g$, separate from the share of medical care it subsidizes.

\subsection{Previous Literature}

Although the general equilibrium effects of Medicare finance are well-recognized (Fuchs, 2000; Saving, 2000), a survey of the existing literature establishes that there has been very little theoretical study in a general equilibrium framework of the multiple health care programs that interact to affect individuals' health and well-being over their entire lives. Such work includes Gecan (1997) and to a lesser extent Bohn (1998). Rather, most studies examine particular health care programs separately. A brief review of the literature establishes why a macroeconomic analysis of the publicly funded health care system may be of value.

Feldstein (1999) examines whether Medicare should continue to be funded by a pay-asyou-go system. He points out that higher taxes will be needed to support this increasingly expensive program and as a result would increase the deadweight losses caused by such a pay- 
as-you-go financing scheme. Thus, Feldstein suggests, as an alternative, a forced saving program where the government saves on behalf of individuals during their working years and then returns the accumulated saving to individuals at retirement so that they can fund their own health care. While his proposal may improve the efficiency with which the program is financed, it takes the social value of the program as given, a position on which we are not as sanguine.

McClellan and Skinner (1997) consider the incidence of Medicare transfers from taxpayers to beneficiaries through the examination of net lifetime tax payments and program expenditures for individuals across various groups. They find that the program has led to net transfers from the poor to the wealthy due to the regressive financing mechanisms as well as higher expenditures and longer survival of the wealthier beneficiaries. Lee, et al. (1999) measure the flow of Medicare benefits among high-income and low-income neighborhoods. Their results suggest that per capita Medicare spending increased much more for low-income neighborhoods than high or middle-income neighborhoods from 1990 to 1995, particularly the home health care spending component of Medicare. They find that the distribution of program benefits may be sensitive to changes in specific components of the program. In these papers the social welfare analysis is implicit, and the true extent of redistribution is left unexamined as Medicaid transfers along with the effects of other government programs are ignored.

Although Medicare is the biggest of the government funded health care programs, Medicaid has also received a fair amount of attention, but again in isolation. Hubbard, et al. (1995) show in the context of a dynamic programming model that the differential wealth between low and high income groups is, in part, a response to means-tested programs such as Medicaid. Much of the research on Medicaid (e.g. Yelowitz (1995), Cutler and Gruber (1996) and Dubay and Kenny (1997)) deals with the policy implications of changes in the various 
institutional details. Although policy conclusions are drawn, they are drawn under the assumption that the partial equilibrium effects dominate the general equilibrium effects.

Gruber and Poterba (1996) examine the effects of employer provided medical benefits. Their results suggest that the current federal tax code does not provide a large subsidy to employer provided insurance because a growing number of employees receive only partial employer benefits and must pay for a portion of their insurance coverage out of after-tax dollars. They also consider possible tax reforms that could cause a substantial number of currently insured workers not to purchase insurance. This could affect the load factor for those that remain in the insured pool and have widespread general equilibrium effects in health insurance markets.

With few notable exceptions, including McClellan, et al. (1997) and Hubbard, et al. (1995), most Medicare/Medicaid studies examine the distributional effects within a generation, but not across generations. While this is reasonable for Medicaid, it is less so for Medicare since it is financed in a pay-as-you-go manner. Since Medicare is just 35 years old, only the newly retired have both paid into the system throughout their working lives and begun to receive benefits from the system. Thus, the lifetime effects of Medicare on these beneficiaries and on social welfare are as yet unknown. They can be examined within the context of the general equilibrium macroeconomic model developed in this paper. Further, since variations of the model are constructed so that some workers receive employer provided benefits, while others receive Medicaid or no benefits at all and all retirees receive Medicare, the social and individual welfare effects of the existing programs, both direct and indirect, can be studied simultaneously. 


\section{The Model}

Consider an infinitely lived economy composed of finitely lived individuals, firms and a government. There are two types of agents: high productivity and low productivity. Denote productivity by $\phi$ and index type by $j=1,2, \phi_{1}>\phi_{2}$. A new generation is born at the beginning of each period $t,(t=1,2,3 \ldots)$ and lives for two periods: youth and retirement. Call this generation $t$. There is no population growth. Without loss of generality assume $N$ of type $j, j=1,2$, are born at each date where $\Sigma N_{j}=1$. In this economy there are two types of goods: non-medical and medical. The non-medical good is produced by firms and either consumed or converted into medical goods by consumers.

\section{Consumers}

Type $j$ agents, $j=1,2$, in the first period of their lives, the young, are endowed with $\phi_{j}$ units of effective labor that they supply inelastically to firms. ${ }^{4}$ They allocate their labor income to saving for retirement, payment of payroll Medicare/Medicaid taxes, and the production of wellbeing, which requires both non-medical ${ }^{5}$ and medical goods as inputs. Consumers produce medical goods from non-medical goods. ${ }^{6}$ Their production may be subsidized by the government via Medicaid, or by an employer via employer provided medical benefits.

With no subsidy of medical expenditures, young agents of type $j$ produce medical goods

\footnotetext{
${ }^{4}$ While recognizing that the existence of job-linked medical benefits can affect an individual's labor supply choice, we assume that labor is inelastically supplied for model tractability.

${ }^{5}$ The non-medical good can be interpreted as a composite good that includes consumption/ nutrition, exercise, and health knowledge. Such life-style factors have been shown to be important determinants of well-being by Gilleskie and Harrison (1998) and Kenkel (1991). Furthermore, non-medical efforts when young may reduce the need for subsequent medical expenditures when old as explored by Grembowski et al. (1993) and Stearns et al. (1998).

${ }^{6}$ Medical goods are consumed as health maintenance/investment when agents are young.
} 
by converting non-medical goods into medical goods at rate $p_{m}^{j}$. With subsidization of medical goods production by Medicaid, at rate $\eta_{j},{ }^{7}$ young agents of type $j$ produce medical goods by converting non-medical goods into medical goods at rate $p_{m}^{j}\left(1-\eta_{j}\right)$. Note, Medicaid will be generally targeted toward the lower productivity/income workers thus implicitly imposing a means-test. The government converts non-medical goods into medical goods for the payment of its Medicaid bill at a rate of $g_{m}^{j}$. With employer provided medical benefits, the agent's own current medical care choice, $m_{t}^{j}(t)$, is augmented by the employer benefit, $m .^{8}$ These benefits are converted from non-medical goods into medical goods by the employer at a rate of $p_{f}^{j}$.

At the beginning of the second period of a type $j$ agent's life she will contract an illness of type $i$, with probability $\pi_{i}, i=1,2 .{ }^{9}$ The illnesses vary in severity, with $i=1$ representing a minor illness, and $i=2$ representing a relatively more serious illness. Each illness $i$ is of the same severity for all agents. ${ }^{10}$ Agents allocate their accumulated saving to non-medical goods and the production of medical goods. Medicare subsidizes the production of medical goods alone.

\footnotetext{
${ }^{7}$ We allow for type j specific Medicaid/Medicare subsidy rates to allow for program variation such as means-tested subsidy rates which will be explored later in the paper. However, we should note that in this framework we cannot analyze the further distortions that a means-tested program may have on labor supply and saving behavior.

${ }^{8}$ An examination of the empirical research suggests that employers use a range of contribution formulas to determine employer and employee shares, e.g. it may be that employers apply different contribution rules for managers vs. workers. In a sample of establishments with multiple, non-self insured plans offered, $26 \%$ of employers pay a fixed dollar contribution, $20.5 \%$ pay a fixed percentage contribution, $16.9 \%$ pay all regardless of which plan the employee chooses and 36.6\% employers use another contribution method (Vistnes, et al. 2000).

${ }^{9}$ The probability of an illness is exogenous and is not a function of well-being when young. The extent of the effect of well-being when young on the probability of an illness when old is unclear and further, endogenous probabilities are not tractable in this model. However, intergenerational links are included in this model since well-being when young directly impacts well-being when old.

${ }^{10}$ Differential morbidity across type $\mathrm{j}$ agents can easily be added to the model whereby illnesses vary by severity as well as by type of agent such that the probability of illness in old age is $\pi_{i j}$. This addition to the model adds complexity without qualitatively changing the results of the paper.
} 
Old agents of type $j$ produce medical goods by converting non-medical goods into medical goods at a rate of $p_{i m}^{j}$. Under Medicare, subsidization of medical care is universal for all old, for any type $j$ and illness $i$, at a rate of $\sigma_{j}$. Thus, all old pay a fraction $\left(1-\sigma_{j}\right)$ of their medical costs, no matter what illness they face. The government converts non-medical goods into medical goods for the payment of its Medicare bill at a rate of $g_{i m}^{j}$.

Let the representative type $j$ member of generation $t$ 's preferences be represented by

$$
U^{j}(t)=\ln h_{t}^{j}(t)+\beta \sum_{i} \pi_{i} \ln h_{i t}^{j}(t+1)
$$

where $h_{t}^{j}(t)$ is the well-being of a type $j$ member of generation $t$ while young, $h_{i t}^{j}(t+1)$ is the well-being of a type $j$ member of generation $t$ with illness $i$ while old, and $\beta$ is the discount rate.

Assume that a young type $j$ member of generation $t$ produces the composite good, wellbeing in youth, by combining medical inputs, $m_{t}^{j}(t)$, (and if present, employer provided medical benefits, $m$ ) and non-medical inputs, $e_{t}^{j}(t)$, using a constant-returns-to-scale production function. Specifically, $h_{t}^{j}(t)=\left(m_{t}^{j}(t)+m\right)^{\alpha_{t}} e_{t}^{j}(t)^{1-\alpha_{t}}$ where $\alpha_{1} \in[0,1]$. Similarly, an old type $j$ member of generation $t$ with illness $i$ produces the composite good, well-being in old age, by combining medical inputs, $m_{i t}^{j}(t+1)$, non-medical inputs, $e_{i t}^{j}(t+1)$, and well-being in youth, $h_{t}^{j}(t)$, using a constant-returns-to-scale production function. Illness $i$ shocks affect both the medical and non-medical components of the production of well-being. The portion of illness $i$ shock that affects medical inputs is $\vartheta_{i m}$ while the portion that affects non-medical inputs is $\vartheta_{i e}{ }^{11}$

\footnotetext{
${ }^{11}$ Many illnesses affect not only the medical component of well-being but also the non-medical component. Examples of shocks to the non-medical component include the inability to cook one's own meals, bathe or dress oneself or to do the grocery shopping.
} 
Specifically, $h_{i t}^{j}(t+1)=h_{t}^{j}(t)^{\gamma_{1}}\left(m_{i t}^{j}(t+1)-\vartheta_{i m}\right)^{\gamma_{2}}\left(e_{i t}^{j}(t+1)-\vartheta_{i e}\right)^{1-\gamma_{1}-\gamma_{2}}$ where $\gamma_{1}, \gamma_{2} \in[0,1]$ and $\gamma_{1}+\gamma_{2}<1$

The representative type $j$ agent at date $t$ takes as given the return to saving when old, $(1+\rho(t+1))$, the wage rate, $w(t)$, and the tax rate, $\tau(t)$. She chooses medical care when young, $m_{t}^{j}(t)$, and old, $m_{i t}^{j}(t+1)$, across all illnesses $i$, non-medical goods when young, $e_{t}^{j}(t)$,

and old, $e_{i t}^{j}(t+1)$, across all illnesses $i$, and saving, $s^{j}(t)$, to maximize (1) subject to (2)-(5).

$$
\begin{aligned}
& h_{t}^{j}(t)=\left(m_{t}^{j}(t)+m\right)^{\alpha_{1}} e_{t}^{j}(t)^{1-\alpha_{t}} \\
& \left(\phi_{j} w(t)-p_{f}^{j} m\right)(1-\tau(t))=\left(1-\eta_{j}\right) p_{m}^{j} m_{t}^{j}(t)+e_{t}^{j}(t)+s^{j}(t), \quad m_{t}^{j}(t) \geq 0 \\
& h_{i t}^{j}(t+1)=h_{t}^{j}(t)^{\gamma_{1}}\left(m_{i t}^{j}(t+1)-\vartheta_{i m}\right)^{\gamma_{2}}\left(e_{i t}^{j}(t+1)-\vartheta_{i e}\right)^{1-\gamma_{1}-\gamma_{2}} \\
& (1+\rho(t+1)) s^{j}(t)=\left(1-\sigma_{j}\right) p_{i m}^{j} m_{i t}^{j}(t+1)+e_{i t}^{j}(t+1)
\end{aligned}
$$

The first-order conditions of the representative type $j$ agent's problem with respect to $s^{j}(t), m_{t}^{j}(t)$, and $m_{i t}^{j}(t+1)$, respectively, are

$$
\begin{aligned}
& \frac{-\left(1-\alpha_{1}\right)\left(1+\beta \gamma_{1}\right)}{\left(\phi_{j} w(t)-p_{f}^{j} m\right)(1-\tau(t))-s^{j}(t)-(1-\eta) p_{m}^{j} m_{t}^{j}(t)}+ \\
& \sum_{i} \frac{\pi_{i} \beta\left(1-\gamma_{1}-\gamma_{2}\right)(1+\rho(t+1))}{(1+\rho(t+1)) s^{j}(t)-(1-\sigma) p_{i m}^{j} m_{i t}^{j}(t+1)-\vartheta_{i e}}=0 \\
& \frac{\alpha_{1}}{m+m_{t}^{j}(t)}-\frac{\left(1-\alpha_{1}\right)(1-\eta) p_{m}^{j}}{\left(\phi_{j} w(t)-p_{f}^{j} m\right)(1-\tau(t))-s^{j}(t)-(1-\eta) p_{m}^{j} m_{t}^{j}(t)}=0 \\
& \frac{\gamma_{2}}{m_{i t}^{j}(t+1)-\vartheta_{i m}}-\frac{\left(1-\gamma_{1}-\gamma_{2}\right)(1-\sigma) p_{i m}^{j}}{(1+\rho(t+1)) s^{j}(t)-(1-\sigma) p_{i m}^{j} m_{i t}^{j}(t+1)-\vartheta_{i e}}=0, \mathrm{i}=1,2 .
\end{aligned}
$$

Substituting (7) and (8) into (6) and simplifying, we have (9) 


$$
\begin{aligned}
& \frac{-\left(1+\beta \gamma_{1}\right)}{\left(\phi_{j} w(t)-p_{f}^{j} m\right)(1-\tau(t))-s^{j}(t)+(1-\eta) p_{m}^{j} m}+ \\
& \sum_{i} \frac{\pi_{i} \beta(1+\rho(t+1))\left(1-\gamma_{1}\right)}{(1+\rho(t+1)) s^{j}(t)-\vartheta_{i e}-(1-\sigma) p_{i m}^{j} \vartheta_{i m}}
\end{aligned}=0
$$

\section{Firms}

The firms in this economy are perfectly competitive profit maximizers that produce a single non-medical good using the constant returns to scale production function $Y(t)=A K(t)^{v}\left(\sum_{j} N_{j} \phi_{j}\right)^{1-v}$ where $A>0$ is a productivity constant, $K(t)$ is the capital stock at date $t$ and $\sum_{j} N_{j} \phi_{j}$ is effective labor at date $t$. Effective labor is comprised of labor hours, $N_{j}$, and the productivity, $\phi_{j}$, of each type of agent. Capital fully depreciates in the production process.

The representative firm takes wages and rental rates as given and hires effective labor from each type and capital until their marginal products equal their factor prices.

$$
\begin{aligned}
& w(t)=(1-v) A K(t)^{v}\left(\sum_{j} N_{j} \phi_{j}\right)^{-v} \\
& r(t)=v A K(t)^{v-1}\left(\sum_{j} N_{j} \phi_{j}\right)^{1-v}
\end{aligned}
$$

\section{Government}

The government in this economy imposes a uniform proportional tax $(\tau)$ on the wages of all young workers. ${ }^{12}$ The revenues from this tax support both the Medicare and Medicaid

\footnotetext{
${ }^{12}$ Taxation of savings and/or lump sum taxes on the old (e.g. Medicare, part B premium) can be easily added to the model, both of which cause the old to pay a greater portion of their medical care indirectly via taxation. Such an addition adds complexity to the model without qualitatively changing the results of the paper.
} 
programs. Medicare sets a subsidy rate $\left(\sigma_{j}\right)$ for medical expenditures of the old and the level of benefits each old individual receives is ultimately determined by his/her choice of medical care. ${ }^{13}$ Medicaid also sets a subsidy rate $\left(\eta_{j}\right)$ for medical expenditures of the young and then the level of benefits received will be determined by their choices of medical care. The government funds its current expenditures with current tax receipts as is the case with the existing Medicare and Medicaid programs. Thus, it must adjust the tax rate that all young workers face at each date $t$ to meet the Medicare subsidy bill and the Medicaid subsidy bill, respectively

$$
\begin{aligned}
& \sum_{j} \sum_{i} \sigma_{j} N_{j} \pi_{i} g_{i m}^{j} m_{i, t-1}^{j}(t) \\
& \sum_{j} \eta_{j} N_{j} g_{m}^{j} m_{t}^{j}(t) .
\end{aligned}
$$

Tax revenues will be either a fraction of after medical benefit wages (14) or simply a fraction of wages if $m=0$ (no employer provided medical benefit)

$$
\tau(t) \sum_{j} N_{j}\left(\phi_{j} w(t)-p_{f}^{j} m\right) .
$$

\section{Goods Market Clearing}

The goods market clears when demand for goods equals supply of goods. Goods market clearing implies that the saving of the young today totally determine the capital stock tomorrow.

$$
\sum_{j} N_{j} s^{j}(t-1)=\sum_{j} N_{j} K(t)
$$

and also by arbitrage

\footnotetext{
${ }^{13}$ For simplicity we ignore long-term care for the elderly which is funded, in large part, by Medicaid rather than Medicare. Thus, we also ignore the implications of long-term care expenditures on the well-being of the elderly.
} 


$$
(1+\rho(t))=r(t) .
$$

\section{Steady-State Equilibrium}

Steady-state equilibrium is characterized by equations (17)-(20)

$$
\begin{aligned}
& \frac{-\left(1+\beta \gamma_{1}\right)}{\left(\phi_{j} w-p_{f}^{j} m\right)\left(1-\tau^{*}\right)-s^{j}+(1-\eta) p_{m}^{j} m}+\sum_{i} \frac{\pi_{i} \beta r\left(1-\gamma_{1}\right)}{s^{j} r-\vartheta_{i e}-(1-\sigma) p_{i m}^{j} \vartheta_{i m}}=0 \quad j, i=1,2 \\
& \tau^{*}=\frac{\sum_{j} \sum_{i} \frac{N_{j} \pi_{i} g_{i m}^{j} \sigma_{j}}{\left(1-\sigma_{j}\right)}\left[\frac{\gamma_{2}\left(s^{j} r-\vartheta_{i e}\right)+\left(1-\gamma_{1}-\gamma_{2}\right)\left(1-\sigma_{j}\right) p_{i m}^{j} \vartheta_{i m}}{p_{i m}^{j}\left(1-\gamma_{1}\right)}\right]}{\sum_{j} N_{j}\left(\phi_{j} w-p_{f}^{j} m\right)\left(1+\frac{\eta_{j} \alpha_{1} g_{m}^{j}}{\left(1-\eta_{j}\right) p_{m}^{j}}\right)} \\
& +\frac{\sum_{j} \eta_{j} N_{j} g_{m}^{j}\left[\frac{\alpha_{1}\left(\phi_{j} w-p_{f}^{j} m-s^{j}\right)-\left(1-\alpha_{1}\right)\left(1-\eta_{j}\right) p_{m}^{j} m}{\left(1-\eta_{j}\right) p_{m}^{j}}\right]}{\sum_{j} N_{j}\left(\phi_{j} w-p_{f}^{j} m\right)\left(1+\frac{\eta_{j} \alpha_{1} g_{m}^{j}}{\left(1-\eta_{j}\right) p_{m}^{j}}\right)} \\
& w=(1-v) A\left(\sum_{j} N_{j} s^{j}\right)^{v}\left(\sum_{j} N_{j} \phi_{j}\right)^{-v} \\
& r=v A\left(\sum_{j} N_{j} s^{j}\right)^{v-1}\left(\sum_{j} N_{j} \phi_{j}\right)^{1-v}
\end{aligned}
$$

The model exposition up to this point has been in its most general form and now certain program parameters will be set equal to 0 across different socio-economic groups. Thus, the economy may be a mixed regime with different types of agents receiving different packages of subsidies. Table I summarizes the six variations on the basic model we analyze. Although other subsidy schemes are possible they are not analyzed since they are not observed in practice. In all variations the old receive Medicare, while the subsidies offered to the young vary where $m$ represents employer provided medical benefits and $\eta$ is the Medicaid subsidy rate. 


\section{Social Welfare}

The overarching goal of health care policy is to increase social welfare. Thus, while Medicare was designed to improve the well-being of the old, it was not to be at the price of lower lifetime well-being. Further, while Medicaid was designed to improve the well-being of the poor, the social welfare benefits were intended to exceed the social welfare costs. Since measuring social benefits and social costs is often difficult, policy evaluation often asks only whether the target group's welfare has improved at an acceptable budgetary cost. We, however, can examine how social welfare is affected by these programs. We assume that a set of steadystate social welfare functions can be defined by

$$
W=\sum_{j} \omega_{j} N_{j}\left[\ln h^{j}+\beta \lambda \sum_{i} \pi_{i} \ln h_{i}^{j}\right] \quad j, i=1,2
$$

where $\omega_{j}$ is the weight placed on the well-being of a type $j$ agent, ${ }^{14}$ and $\lambda$ is the weight placed on the well-being of all old agents. ${ }^{15}$ By varying the social welfare weights we define a large class of social welfare functions.

\section{Calibration}

The analytical solutions for the six variations of the model do not generally yield decisive results and so numerical solutions have been sought. ${ }^{16}$ We attempt to calibrate the model to the US economy. In particular, we first focus on the share of income spent on medical care by the young and old in the model. We turn to data from the 1998 Consumer Expenditure Survey

\footnotetext{
${ }^{14}$ Thus, if $\omega_{2}>1$ there is a social concern for the poor that exceeds their weight in the population.

${ }^{15}$ Thus, if $\lambda>1$, there is a social concern for all old that exceeds their weight in the population.

${ }^{16}$ The focus in this paper is on the social welfare of the economy however in another paper that examines these model variations (Bednarek, 1999), comparative static exercises are conducted for the parameters of the model.
} 
(CES) for the share of average net income spent on health care across all age groups and the Health Care Financing Administration (1998) for the share of income spent on health care by those 65 and over across income groups as seen in Tables II and III.

In order for the model economy's share of income spent on health care to match empirical estimates we must adjust the size of the elasticity of well-being with respect to medical care when young $\left(\alpha_{1}\right)$ and when old $\left(\gamma_{2}\right)$ accordingly. While maintaining the assumption of a constant returns to scale well-being production function, the elasticities of well-being with respect to medical care when young and old are set to .10 . This yields shares of medical care for the young from $4-6 \%$ and for the old shares between $13-27 \%$, depending in part on the size of the medical shock. Note, however, that the elasticity of well-being with respect to medical care in our model may not necessarily directly correspond to the elasticity of health with respect to medical care which is what has most often been empirically tested. The estimated elasticity most often quoted by health economists is that from the RAND Health Insurance Experiment, which reports empirical estimates that are not significantly different from zero (Manning et al., 1987). However it could be argued that one's well-being increases as a result of a check-up stating that one is in perfect health, that is the consumption of medical care with no measurable health effects. Empirical estimates of the elasticities with respect to well-being when young and nonmedical care are non-existent. We chose the elasticity of well-being when old with respect to well-being when young $\left(\gamma_{I}\right)$ to be no greater than that of the elasticity of medical care when old $\left(\gamma_{2}\right)$ and then, by our constant returns to scale assumption, the elasticity with respect to nonmedical care $\left(1-\gamma_{1}-\gamma_{2}\right)$ is determined. Sensitivity analyses of the elasticities were done including minimizing or eliminating the link between health when young and well-being when old. The results are qualitatively similar and the findings of this paper hold for a wide range of values. 
Second, setting the proportion of the population in each productivity group $j$ is critical because it determines what medical benefit, the amount those individuals receive as well as the amount of revenue the government needs to raise. For example, if you are a low productivity worker and receive Medicaid implicitly you have satisfied an income-test or if all individuals in the economy receive Medicaid everyone has satisfied an income-test. According to the US Census Bureau, in 1998, approximately $20 \%$ of households had income under $\$ 15,000$. Correspondingly, the proportion of low productivity workers in the model, $N_{2}$, is set to 20 .

The following parameters are those that are relevant for the social welfare policy experiments. We vary the weight on the welfare of the old ranging from 1, 5, 10 and 100 while the weight on the welfare of low productivity workers ranges from .5, 1 and 3 . We have set initial values for the health care program parameters as follows, however since we are searching for optimal subsidy rates, we examine a wide range of values. The Medicare subsidy rate, $\sigma$, is approximately the share of medical expenditures by the old (not including nursing home expenditures) that is paid for by the government (HCFA, 1998; Hahn and Lefkowitz, 1992). The Medicaid subsidy rate, $\eta$, is the share of medical expenditures of the young paid for by Medicaid. ${ }^{17}$ In the model, those that receive the subsidy have implicitly satisfied the income-test criterion. Health care subsidization for the working poor is a relatively new phenomenon, much of it due to the 1996 Welfare-to-Work legislation and programs are very much state-specific. Any changes in the Medicare or Medicaid subsidy rate affect savings and lifetime well-being monotonically for all the simulations conducted in this paper. The employer provided medical

\footnotetext{
${ }^{17}$ Medicaid may be modeled as a direct subsidy/reduction in price of medical care due to the means testing of the program. Individuals may pay for some medical care out-of-pocket before receiving Medicaid (i.e. spend-down), have co-payments or premiums as well as incur implicit costs such as waiting for public medical care or transportation.
} 
benefit, $m$, has been set such that all workers regardless of their productivity level receive the same benefit. Estimates of the share of total compensation that is employer spending on medical benefits range from 6-15\%. In 1998 employer spending on medical benefits was $\$ 333.1$ billion while total compensation was $\$ 5,007.1$ billion so that the share going to employer medical benefits is $6.7 \%$. Other estimates suggest that medical benefits, as a percentage of a worker's total compensation, vary according to the wage and it falls within the range of 3-7\% percent (EBRI, 1997 \& 2000; Bureau of Labor Statistics, 1997). The results of this paper hold independent of the choice of the baseline value of employer provided medical benefits as all changes in savings and well-being are monotonic.

Additional experiments are conducted that examine the effect on program subsidy rates of changes in the disparity of productivity levels $\left(\phi_{1^{-}} \phi_{2}\right)$ as well as government administered prices relative to the price of medical care individuals face ( $g$ vs. $p$ ). The baseline productivity levels were chosen in order to generate sufficiently large differences in income, and thus wellbeing, of various groups. The baseline prices of medical care are all normalized to one. In doing this, the effects of medical subsidies on capital accumulation and well-being are isolated and are not intertwined with any price effects.

Capital's share of output, $v$, and the intertemporal discount rate, $\beta$, have been estimated in numerous studies. The size of the severe shock is such that individuals can recover from it with their own income. The amount that individuals spend on medical or non-medical care is bounded by zero thus, they cannot spend negative amounts on either medical or non-medical care to spend more on the other good. Given this constraint along with the choice of other parameters impacting its value, the severe shock cannot be greater than .04 . Accordingly, the minor shock is adjusted relative to the severe shock. An illness (severe or minor) adversely 
affects both medical and non-medical care by the same amount in the baseline. Varying sizes of shocks to the medical and non-medical components of well-being were explored such that $\theta_{i e}$ may be less than or greater than $\theta_{i m}$. However, there were no significant differences in the results when either of these alternative specifications was considered. Sensitivity analyses on the probability of contracting illness $i$ have been done for the full range (0-1) and suggest similar qualitative results. Further, to ensure that our results are not too sensitive to the set of baseline parameter values we have chosen, we conduct extensive sensitivity analyses. These analyses, available from the authors on request, have convinced us that the results presented below are quite robust. Table IV summarizes the baseline parameters that were used for the calibration.

Results

Result 1 - Medicare: Taking the set of programs as given, and holding the Medicaid subsidy rate and the level of employer provided medical benefits constant, for all variations of the model the optimal Medicare subsidy rate

a) increases as the social welfare weight on the well-being of the old, $\lambda$, increases for all $\lambda>0$. See rows of Table Vi.

b) increases as the government administered price for medical care, $g_{m}^{j}, g_{i m}^{j}$, decreases for all $\lambda>1$. See Table Vi, columns 2-4. For $\lambda=1$, the Medicare subsidy rate remains 0 or increases as the government administered price for medical care decreases. See Table Vi, column 1.

c) decreases as income disparity, $\phi_{1^{-}} \phi_{2}$, increases for all $\lambda>1$. See Table Vii, columns 2-4. For $\lambda=1$, the Medicare subsidy rate remains 0 as income disparity grows. See Table Vii, column 1 .

d) is not affected by changes in the welfare weight on the poor young, $\omega_{2}$.

Empirically the Medicare subsidy rate is approximately 65\% (HCFA, 1998). Result 1 strongly suggests that for such a rate to be optimal, all else equal, the social welfare weight on the utility of the old must exceed unity, unless the government is able to negotiate significantly better prices for medical goods (without causing other distortions in the medical goods market). This suggests that society as a whole puts greater value on the living standards of the elderly than 
of the young. This social valuation could be a result of the voting habits and political activity, a notion further explored in Mulligan and Sala-i-Martin (1999) where the old have a stronger political pressure function which relates political activity and leisure time. Or, it could be a reflection of a negative external effect on the welfare of the young of low living standards of the elderly. Thus, while the young individually cannot affect this, society as a whole can.

For our parameterization and for equal weighting on the welfare of the young and the old, Part $b$ suggests that the government administered price of medical care would have to be approximately $50 \%$ of the market price for the optimal Medicare subsidy rate to be positive. Although positive, this subsidy rate (.38) is still substantially less than what we observe in practice. This is because the deadweight loss imposed by the tax system, through reductions in the equilibrium capital stock, is large. Thus, if the Medicare program is a response to the failure of the market for health insurance for the elderly, ${ }^{18}$ this suggests that the market failure must be relatively severe before pay-as-you-go financed Medicare is welfare improving.

Parts c and d of Result 1 imply that inequality in the income distribution and how the young enter the social welfare calculus have little or no effect on the optimal Medicare subsidy rate, all else equal. What matters almost exclusively is the social welfare weight on the old.

Result 2 - Medicaid: Taking the set of programs as given, (i) assume that only the low productivity workers receive Medicaid (variation 2 or 5). Then, holding the Medicare subsidy rate and the level of employer provided medical benefits constant, the optimal Medicaid subsidy rate

a) decreases as the social welfare weight on the well-being of the old, $\lambda$, increases for all $\lambda>0$. See rows of Table VIi.

\footnotetext{
${ }^{18}$ Our model can be reinterpreted to allow for adverse selection and market failure. Suppose at birth each agent knows his productivity type but not his "health-type" when old. Upon retirement, each individual realizes his health-type (prior to the realization of the shock), and this information is private. Since insurers cannot distinguish between good and bad risks there is adverse selection and so the possibility of market failure.
} 
b) increases as the government administered price for medical care, $g_{m}^{j}, g_{i m}^{j}$, decreases. See columns of Table VIi.

c) increases as income disparity, $\phi_{1^{-}} \phi_{2}$, increases. See Table VIii.

d) increases as the welfare weight on the poor young, $\omega_{2}$, increases. See Table VIiii. (ii) now assume that all young receive Medicaid (variation 3). Then the optimal Medicaid subsidy rate is zero for all social welfare weighting schemes $\left(\lambda, \omega_{2}\right)$ and income distributions $\left(\phi_{1^{-}} \phi_{2}\right)$ and government administered prices for medical care $\left(g_{m}^{j}, g_{1 m}^{j}, g_{2 m}^{j}\right)$ that are relatively close to the market price for medical care.

We observe that when only low productivity workers, i.e., the poor, receive Medicaid, all else equal, the system redistributes resources from the rich to the poor, increasing the welfare of the poor. This redistribution is social welfare enhancing, although it reduces the lifetime wellbeing of the relatively well-off. However, the poor must compete with the old in the welfare calculus. Thus, the more weight placed on the welfare of the old, the more difficult it is to achieve a welfare enhancing transfer from the rich young to the poor young. The baseline Medicaid subsidy rate is .5 in our model, although with the recent welfare reform it is difficult to gauge empirically the subsidy rate. For this subsidy rate to be (approximately) optimal it must be the case that, all else equal, the government administered price is less than the market price or that the poor are overweighted in the social welfare calculus. Should income dispersion increase, the optimal Medicaid subsidy rate increases in variations where only low productivity workers receive Medicaid. This result is not surprising since if there were no income dispersion there would be no need for redistribution. The optimal income taxation literature discusses this at length, for example, Stern (1976).

When all young qualify for Medicaid and the price of government provided medical care is equal to the private sector price, the young pay in full for the Medicaid benefits they receive and so the optimal subsidy rate is zero, as the uniformly applied program simply mimics the market. Clearly, when the government administered price is sufficiently lower than the market 
for the same care, because, for example, of its ability to mandate coverage and so pool risk (not modeled), the optimal Medicaid subsidy will be positive.

Result 3 - Employer Provided Medical Benefits: Holding the Medicare and Medicaid subsidy rates constant, there is no social welfare gain from firm provided employer provided medical benefits for all social welfare weights on the old $(\lambda)$, income distributions $\left(\phi_{1^{-}} \phi_{2}\right)$, and welfare weight on the poor young $\left(\omega_{2}\right)$ unless $p_{f}^{j}<p_{m}^{j}$.

The tax treatment of medical benefits is social welfare reducing since it makes the funding of Medicare and Medicaid more regressive. For employer provided benefits to be social welfare enhancing, it must be the case that firms' can buy medical care at a lower price, $p_{f}^{j}$, than their employees' on own account, as a result of, for example, risk pooling, or the ability to reduce the transactions associated with medical care provision. This price effect is borne out in our simulations. Employer medical benefits have been estimated to be anywhere from 3-12\% of an employee's wage. Our model allows for employer provided benefits to vary over the range of empirical estimates though such variation has little effect on social welfare (with the exception of firms having a price advantage). ${ }^{19}$

We now ask if Medicare is available to all old agents, should all receive it, and if so, what is the optimal subsidy rate for each type of agent?

Result 4 - Means Testing: For all $\lambda$, the optimal Medicare subsidy rate for the poor exceeds the optimal Medicare subsidy rate for the rich.

\footnotetext{
${ }^{19}$ If the poor were given the option of either receiving employer provided benefits or Medicaid, for many parameterizations of the model Medicaid is preferred. However, if the social welfare weight on the old is greater than their population weight, there is no "crowd-out" effect in terms of social welfare because employer provided benefits are preferred regardless of the Medicaid subsidy rate.
} 
This result, Table VII, suggests that Medicare should be means-tested. If subsidy rates are at optimal levels, both rich and poor are better off under means testing relative to a uniform rate. When Medicare benefits are means-tested, the tax rate levied on all young is reduced because the bill for the program is reduced. This tax reduction enables both rich and poor to produce more medical goods, and save more for retirement. Further, with equal weight on the welfare of the old and young and when the government does not enjoy a price advantage over the market, social welfare is optimized without Medicare for the rich, which is never true for the poor. But, as the weight on the welfare of the old in the social welfare function increases, all individuals under-invest in own well-being relative to the social optimum. Medicare corrects this. Suppose, as is often argued, that means-testing is not a politically viable option, but making the tax system more progressive is.

Result 5 - Progressive Taxation: For any feasible uniform Medicare and Medicaid subsidy rates, a progressive tax structure is social welfare enhancing in all model variations except variation 3 (where all individuals receive both Medicare and Medicaid subsidies).

The optimality of the progressive tax arises since, moving away from a uniform tax rate, for a fixed subsidy rate, the marginal welfare gain to the poor is greater than the marginal welfare cost to the rich. See Table VIII. This is not the case in variation 3 where the benefit structure is identical and the tax burden for both groups is too great to yield welfare gains for either group.

\section{Alternative Health Care Programs}

We now explore alternative health care program financing and its impact relative to existing programs. We examine two specific changes that have been proposed as alternatives to parts of the current programs: Medical Savings Accounts (MSA) for the young and a defined 
contribution/forced saving program for the medical care of the old ${ }^{20,21}$. MSAs are tax-favored funds that can be used to pay current and potentially future out-of-pocket medical costs. Often these accounts are in conjunction with a high deductible catastrophic insurance plan. ${ }^{22}$ The argument for such a program is that individuals then face the true price of medical care (minus the tax-preferential treatment) and their behavior is not distorted: they will not choose to overconsume medical care. The Health Insurance and Portability and Accountability Act of 1996 authorized a pilot program that was to expire at the end of 2000 but Congress extended until the end of 2002, whereby eligible individuals can choose the MSA option. The forced saving mechanism is in the spirit of Feldstein's (1999) Retiree Health Accounts (RHAs) whereby individuals, when young, save in a tax-deferred account for their medical care when old. Unlike Feldstein, we do not include a direct government contribution to the account.

First, Medical Savings Accounts (MSAs) are included as an alternative to Medicaid or employer provided medical benefits for young workers. Workers choose how much medical care they want and its cost is deducted from before-tax earnings versus after-tax earnings. There is no fungibility of the funds saved in the MSA as they are restricted to medical care only. We make comparisons to other variations where MSAs are available for all young in the economy or only for the poor (for example, in lieu of Medicaid).

If MSAs are available to all young in the economy then the appropriate comparison variations 1, 3 and 6. Comparisons across these variations show that with equal weight on the young and the old, social welfare can be ranked from highest to lowest: variation 6 (employer

\footnotetext{
${ }^{20}$ We thank one of the referees for suggesting the examination of these alternative financing mechanisms relative to the existing scheme.

${ }^{21}$ The model specifications for these variations of health care financing are available from the authors upon request.

${ }^{22}$ Such a high deductible catastrophic insurance policy is not modeled here for tractability.
} 
provided medical benefits to all young), variation 1 (no benefits for any young), MSA variation and then variation 3 (Medicaid to all young). This ranking can be interpreted as follows. In variation 6 all young get the same employer provided medical benefits, so the effect of higher Medicare taxes falls disproportionately on the high productivity young because they receive a smaller tax break as a percentage of their income, thereby inducing intra- and well as intergenerational redistribution. Since all young receive the benefit of before-tax dollars for the employer provided medical care, although they face a higher Medicare tax rate as a result, the benefit exceeds the costs, as can be seen since social welfare is lower under variation 1 where the tax effect is equally distributed but the price of medical care is effectively higher. Under the MSA scheme the relative price of medical care when young is lower and individuals spend more. This is because agents choose how much to spend on medical care and its cost is out of beforerather than after-tax income which increases the Medicare tax and reduces the relative price of medical care when young still more. The net effect is lower social welfare, and the reason is the Medicare tax distortion. Tax distortions are even worse when all the young get Medicaid.

If MSAs are available only to poor workers while employer provided benefits are available to rich workers then comparisons can be made to variations 4 (poor young's medical care is not subsidized), and 5, (poor young receive Medicaid). If the old and the young are given equal social welfare weighting then it is not surprising that the most generous variation in terms of benefits to the young, variation 5, yields the greatest social welfare. This is because intragenerational redistribution (from rich young to poor young) is social welfare improving, and variation 5 is the most redistributive of the three variations. This continues to hold as the welfare weight on the poor young increases. But as the social welfare weight on old increases, the social welfare benefit of intragenerational redistribution falls. In this case the MSA variation provides 
a lower level of intragenerational redistribution by shifting, to a lesser extent, the tax burden of Medicare to the high productivity young. When $\lambda=5$ the MSA scheme yields the greatest social welfare. If the welfare weight on the old equals or exceeds 10 , variation 4 , where there is no government subsidization of medical care for poor young, yields the greatest social welfare, since intergenerational (transfer from young to old for Medicare) concerns overwhelm intragenerational ones (transfer from rich young to poor young) in the welfare calculus.

Our analysis of MSA programs for the young suggest that they can be welfare improving, but may need to be carefully designed to protect against overconsumption of medical care when young. For example, by capping a MSA at a contribution equal the contribution made by employers under the current tax sheltered system, social welfare could be improved relative to the Medicaid program or to the market outcome.

Second, we examine the concept of a forced saving program, which can be thought of as a defined contribution plan targeted for medical care expenditures. Individuals set aside part of their pre-tax earnings when young for medical care when old. When old, individuals receive those funds back with interest to be spent on medical care only. Since this forced saving mechanism replaces the Medicare program, we can compare economies with forced saving for all old, economies with Medicare for all old (all variations), and economies with no government programs for the old $(\sigma=0)$. If we value the young and old equally, then an economy with no government programs for the old yields the greatest social welfare. However as we increase the welfare weight of the old, programs that subsidize the medical care of the old look more favorable. If $\lambda=5$ then, an economy with a forced saving program yields the greatest social welfare. For $\lambda \geq 10$, an economy with Medicare yields the greatest social welfare. Medicare allows the greatest government subsidization as a direct subsidy to an individual's choice of 
medical care relative to the indirect subsidy provided by the tax sheltered forced saving program. For moderate social welfare weights on the well-being of the old, social welfare improvements can be won by forcing the old to self-finance at least some of their medical care by saving when young. ${ }^{23}$ How much self-finance is optimal depends on the value placed on the welfare of the old and the extent of the distortions caused by the intergenerational financing of Medicare.

\section{Conclusion}

In this paper we have developed a general equilibrium model in which the social welfare effects of the two major government health care programs, Medicare and Medicaid, and the special tax treatment of employer provided medical benefits can be simultaneously evaluated. We find for Medicare to be optimal and to be funded in a pay-as-you-go manner, the government administered price of medical care must be at a significant discount from the market price or that the elderly are over-weighted in the social welfare function. Further, the program should be redistributive from the rich to the poor, and, holding the tax rate constant, means-tested. This puts the ideal and the actual at odds. McClellan and Skinner (1997) find that Medicare redistributes resources from the poor to the rich. Further, while President Clinton suggested expanding Medicare to cover prescription drugs, he rejected means-testing benefits.

Medicaid, the smaller of the two programs, does not have a constituency with the wherewith all to fight for maintenance or expansion of benefits. We find that it is not optimal to expand this program to both the rich and poor young as the additional tax burden of a National

\footnotetext{
${ }^{23}$ Similar welfare gains are possible by imposing either lump-sum or proportional taxes on the income of the old, but again only if the old and the young receive approximately equal weight in the welfare calculus. As the weight on the old rises, social welfare falls: all are better off with the original tax structure.
} 
Health-like scheme is so great that it is social welfare reducing. When designated for the working poor without employer provided medical benefits, our results suggest that this program is social welfare enhancing via redistributions from the rich young to the poor young. To achieve these results we need not over-weight the welfare of the poor nor do we need an overly large income disparity. Further, a price advantage for the government is not required. That is to say, the results are very robust to variations of the model. Medicaid, our results suggest, should be maintained. However, should the public will go against Medicaid, a Medical Savings Account plan can supplant it and, potentially, increase social welfare.

The tax treatment of employer provided medical benefits has an interesting history. Begun during World War II as a way around wage and price controls, it has since taken on a life of its own as an important part of many wage bargains. As health care costs have increased employers have substituted money wages for benefits, providing employees with an expanded set of health care options, but out of after-tax wages. This change in the structure of total compensation improves the equitability of treatment of all taxpayers, since those who do not receive employer provided benefits paid taxes on all their wages rather than only on their wages net of health care. Further, to the extent that employers can negotiate better health care benefits than can individuals on own account, employees still receive the price discount, which is welfare improving. Our results suggest that current trends are welfare improving.

Overall our analysis suggests that the steady-state macroeconomic effects of publicly provided health care can be social welfare improving, but the current system deviates from optimality. Moreover, demographic trends place two stresses on the system. As individuals live longer their medical expenditures rise, increasing the cost of the Medicare program. Further, as the aged-dependency ratio rises, there are fewer young workers to pay for the Medicare program. 
What these trends mean for optimal program design as well as any transitions from one variation to another, at least in a macroeconomic context, is left for future research. 


\section{References}

Bednarek, Heather L. (1999) Essays on Medicaid and its Populations, PhD dissertation, Michigan State University.

Bohn, Henning (1999) "Will Social Security and Medicare Remain Viable as the US Population Ages?" Carnegie Rochester Conference Series on Public Policy 50, 1-53.

Bureau of Labor Statistics (1997) Employee Benefits in Medium and Large Private Establishments, U.S. Government Printing Office.

Consumer Expenditure Survey (1998) ftp.bls.gov/pub/special.requests/ce.

Cutler, D. (2000) "Walking the Tightrope on Medicare Reform," Journal of Economic Perspectives 14, 45-56.

Cutler, D. and J. Gruber (1996) "Does Public Insurance Crowd Out Private Insurance?" Quarterly Journal of Economics 111, 391-430.

Dubay, L., and G. Kenney (1997) "Did Medicaid Expansions For Pregnant Women Crowd Out Private Coverage?” Health Affairs 16, 185-206.

Economist (1999) “Medicare Reform: Promises, Promises,” 350, 29-30.

Ellwood, M. (1999) "The Medicaid Eligibility Maze: Coverage Expands but Enrollment Problems Persist, Findings from a Five-State Study," Urban Institute Manuscript.

Employee Benefit Research Institute (1997) EBRI Databook on Employee Benefits, fourth edition, Washington D.C.

Employee Benefit Research Institute (2000) EBRI Notes, July 2000, Washington D.C.

Feldstein, M. (1999) “Prefunding Medicare,” American Economic Review 89, 222-27.

Fuchs, V. (2000) "Medicare Reform: The Larger Picture," Journal of Economic Perspectives $14,57-70$.

Gecan, Ronald (1997) A General Equilibrium Analysis of Medicaid and Medicare, $\mathrm{PhD}$ dissertation, University of Minnesota.

Gilleskie, D.B. and A.L. Harrison (1998) "The Effect of Endogenous Health Inputs on the Relationship between Health and Education," Economics of Education Review 17, 27995.

Grembowski, D., D. Patrick, P. Diehr, et al. (1993) "Self-efficacy and Health Behavior Among Older Adults," Journal of Health and Social Behavior 34, 89-104. 
Gruber, J. and J. Poterba (1996) "Tax Subsidies to Employer Provided Health Insurance," Empirical Foundations of Household Taxation, M. Feldstein and J. Poterba, eds., University of Chicago Press.

Hahn, B and D. Lefkowitz (1992) "Annual Expenses and Sources of Payment for Health Care Services" (AHCPR Pub. No. 93-0007), National Medical Expenditure Survey Research Findings 14, Agency for Health Care Policy and Research, Rockville, MD: Public Health Service.

Health Care Financing Administration (1998) A Profile of Medicare, Baltimore MD.

Health Care Financing Administration (1999) Health Reform Demonstration Fact Sheets for 50 States 1115 Waivers, Baltimore MD.

Hubbard, R.G., J. Skinner, and S.P. Zeldes (1995) "Precautionary Savings and Social Insurance," Journal of Political Economy 10, 360-99.

Lee, J., M. McClellan, and J. Skinner (1999) "Distributional Effects of Medicare," Tax Policy and the Economy 13, J Poterba, ed., MIT Press.

Kenkel, D.S. (1991) "Health Behavior, Health Knowledge, and Schooling," Journal of Political Economy 99, 287-305.

Manning, W.G., J. Newhouse, N. Duan, E. Keeler, A. Leibowitz (1987) "Health Insurance and the Demand for Medical Care: Evidence from a Randomized Experiment," American Economic Review 77, 251-77.

McClellan, M. (2000) "Medicare Reform: Fundamental Problems, Incremental Steps," Journal of Economic Perspectives 14, 21-44.

McClellan, M., and J. Skinner (1997) “The Incidence of Medicare,” NBER Working Paper \#6013.

Mulligan, C.B., and X. Sala-i-Martin (1999) "Gerontocracy, Retirement and Social Security," University of Chicago Center for the Study of the Economy and the State Working Paper \#154.

Reinhardt, U. (2000) "Health Care for the Aging Baby Boom: Lessons from Abroad," Journal of Economic Perspectives 14, 71-84.

Saving, T. (2000) "Making the Transition to Prepaid Medicare," Journal of Economic Perspectives 14, 85-98.

Stearns, S.C., S. Bernard, S. Fasick, R.R. Konrad, R. Schwartz, and G.H. Defriese (1998) "The Effect of Self-Care Practices on Medicare Reimbursement," Draft paper, UNC. 
Stern, N.H. (1976) "On the Specification of Models of Optimum Income Taxation," Journal of Public Economics 6, 123-62.

U.S. Census Bureau (1999) Statistical Abstract of the United States: 1999, Section 14, U.S. Government Printing Office.

Vistnes, J.P., P.F. Cooper, G.S. Vistnes (2000) "Employer Contribution Methods and Health Insurance Premiums: Does Managed Competition Work?” Draft paper, AHRQ.

Yelowitz, A (1995) “The Medicaid Notch, Labor Supply, and Welfare Participation:

Evidence from Eligibility Expansions," Quarterly Journal of Economics 110, 909-39. 
Table I. Six variations on the basic model

\begin{tabular}{|c|l|l|}
\hline \hline \multirow{2}{*}{ Variation } & \multicolumn{2}{|c|}{ Hubsidy Package } \\
\hline 1 & \multicolumn{1}{|c|}{ Ho Pubsidy: $m \& \eta_{1}=0$} & Low Productivity Workers \\
\hline 2 & No subsidy: $m \& \eta_{1}=0$ & Medicaid: $m=0 \& \eta_{2}>0$ \\
\hline 3 & Medicaid: $m=0 \& \eta_{1}>0$ & Medicaid: $m=0 \& \eta_{2}>0$ \\
\hline 4 & $\begin{array}{l}\text { Employer provided medical benefits: } \\
\mathrm{m}>0 \& \eta_{1}=0\end{array}$ & No subsidy: $m \& \eta_{2}=0$ \\
\hline 5 & $\begin{array}{l}\text { Employer provided medical benefits: } \\
\mathrm{m}>0 \& \eta_{1}=0\end{array}$ & Medicaid: $m=0 \& \eta_{2}>0$ \\
\hline 6 & $\begin{array}{l}\text { Employer provided medical benefits: } \\
\mathrm{m}>0 \& \eta_{1}=0\end{array}$ & $\begin{array}{l}\text { Employer provided medical benefits: } \\
m>0 \& \eta_{2}=0\end{array}$ \\
\hline
\end{tabular}


Table II. Share of average annual net income spent on health care by age group

\begin{tabular}{|l|c|}
\hline \hline under 25 & $2.8 \%$ \\
\hline $25-34$ & $3.1 \%$ \\
\hline $35-44$ & $3.6 \%$ \\
\hline $45-54$ & $4.1 \%$ \\
\hline $55-64$ & $5.3 \%$ \\
\hline $65+$ & $12.8 \%$ \\
\hline \hline \multicolumn{2}{|l|}{ Source: CES (1998) } \\
\hline
\end{tabular}


Table III. Share of average annual income spent on health care for those 65 and over by income group

\begin{tabular}{|l|c|}
\hline \hline$<11,000$ & $24.9 \%$ \\
\hline$\$ 11-21,000$ & $19.1 \%$ \\
\hline$\$ 21-34,000$ & $11.6 \%$ \\
\hline$\$ 34-54,000$ & $8.3 \%$ \\
\hline$>\$ 54,000$ & $3.6 \%$ \\
\hline \multicolumn{2}{|l|}{ Source: HCFA (1998) } \\
\hline
\end{tabular}


Table IV. Parameters for calibration

\begin{tabular}{|l|l|}
\hline \hline Medicare subsidv rate & $\sigma=65$ \\
\hline Medicaid subsidy rate (to those that meet the income-test) & $\eta=.5$ \\
\hline Employer provided medical benefit & $m=.015$ \\
\hline Price of medical care for young workers & $p_{m}^{j}=1$ \\
\hline Price of medical care that firms pay for the medical benefit they give to workers & $p_{f}^{j}=1$ \\
\hline Price of medical care for the old that contract the relatively minor illness & $p_{1 m}^{j}=1$ \\
\hline Price of medical care for the old that contract the more severe illness & $p_{2 m}^{j}=1$ \\
\hline Cost of govt medical care reimbursement of the young & $\mathrm{g}^{\mathrm{j}}=1$ \\
\hline Cost of govt medical care reimbursement of the old that contract minor illness & $g_{1 m}^{j}=1$ \\
\hline Cost of govt medical care reimbursement of the old that contract severe illness & $g_{2 m}^{j}=1$ \\
\hline Productivity level for high productivity workers & $\phi_{l}=2$ \\
\hline Productivity level for low productivity workers & $\phi_{2}=1$ \\
\hline Probability of contracting illness i & $\pi_{i}=.5$ \\
\hline Proportion of the population in each productivity group i (sums to one) & $N_{l}=.8, N_{2}=.2$ \\
\hline $\begin{array}{l}\text { Size of the relatively minor shock when old (affects both medical and non- } \\
\text { medical components of well-being) }\end{array}$ & $\theta_{1 e}=\theta_{l m}=.02$ \\
\hline $\begin{array}{l}\text { Size of the more severe shock when old (affects both medical and non-medical } \\
\text { components of well-being) }\end{array}$ & $\theta_{2 e}=\theta_{2 m}=.04$ \\
\hline Elasticity of well-being when young with respect to medical care & $\alpha_{I}=.10$ \\
\hline $\begin{array}{l}\text { Elasticity of well-being when old with respect to well-being when young and } \\
\text { medical care }\end{array}$ & $\gamma_{I}=\gamma_{2}=.10$ \\
\hline Capital's share of output & $\mathrm{v}=.3$ \\
\hline Intertemporal discount rate & $\beta=.5$ \\
\hline Total factor productivity & $A=1$ \\
\hline \hline
\end{tabular}


Table V. Optimal Medicare subsidy rate $(\sigma) *$

i. Effect of variation in government price of medical care on optimal Medicare subsidy rate

\begin{tabular}{|c|c|c|c|c|c|}
\hline \multirow{2}{*}{\multicolumn{2}{|c|}{$\begin{array}{l}\text { Government administered price for medical care }\left(g_{m}^{j}, g_{i}^{j}\right) \\
\text { relative to the price that the individual faces }\left(p_{m}^{j}, p_{i}^{j}\right) \\
\mathrm{i}=1,2\end{array}$}} & \multicolumn{4}{|c|}{ optimal Medicare subsidy rate $(\sigma)$} \\
\hline & & $\lambda=1$ & $\lambda=5$ & $\lambda=10$ & $\lambda=100$ \\
\hline$g_{m}^{j}, g_{i m}^{j}=1.25$ & $\mathrm{p}_{\mathrm{m}}^{\mathrm{j}}, p_{i m}^{j}=1$ & 0 & .42 & .56 & .67 \\
\hline$g_{m}^{j}, g_{i m}^{j}=1$ & $\mathrm{p}_{\mathrm{m}}^{\mathrm{j}}, p_{i m}^{j}=1 \quad$ (baseline) & 0 & .54 & .64 & .74 \\
\hline$g_{m}^{j}, g_{i m}^{j}=.75$ & $\mathrm{p}_{\mathrm{m}}^{\mathrm{j}}, p_{i m}^{j}=1$ & 0 & .65 & .73 & .80 \\
\hline$g_{m}^{j}, g_{i m}^{j}=.50$ & $\mathrm{p}_{\mathrm{m}}^{\mathrm{j}}, p_{i m}^{j}=1$ & .38 & .77 & .82 & .86 \\
\hline
\end{tabular}

ii. Effect of income disparity on optimal Medicare subsidy rate

\begin{tabular}{|l|l|l|l|l|}
\hline \hline Income disparity between high and low productivity & \multicolumn{4}{|c|}{ optimal Medicare subsidy rate $(\sigma)$} \\
\cline { 2 - 6 } workers $\left(\phi_{1}-\phi_{2}\right)$ & $\lambda=1$ & $\lambda=5$ & $\lambda=10$ & $\lambda=100$ \\
\hline$\phi_{1}-\phi_{2}=1 \quad$ (baseline) & 0 & .54 & .64 & .74 \\
\hline$\phi_{1}-\phi_{2}=5$ & 0 & .51 & .62 & .72 \\
\hline
\end{tabular}

*These results are for the baseline variation (variation 5) but they qualitatively apply to all 6 of the variations with similar quantitative results. 
Table VI. Optimal Medicaid subsidy rate $(\eta) * *$

i. Effect of variation in government price of medical care on optimal Medicaid subsidy rate

\begin{tabular}{|c|c|c|c|c|}
\hline $\begin{array}{l}\text { Government administered price for medical care }\left(g_{m}^{j}, g_{i}^{j}\right) \\
\text { relative to the price that the individual faces }\left(p_{m}^{j}, p_{i}^{j}\right)\end{array}$ & \multicolumn{4}{|c|}{ optimal Medicaid subsidy rate $(\eta)$} \\
\hline & $\lambda=1$ & $\lambda=5$ & $\lambda=10$ & $\lambda=100$ \\
\hline$g_{m}^{j}, g_{i m}^{j}=1.25 \quad \mathrm{p}_{\mathrm{m}}^{\mathrm{j}}, p_{i m}^{j}=1$ & .28 & .04 & 0 & 0 \\
\hline $\mathrm{p}_{\mathrm{m}}^{\mathrm{j}}, p_{i m}^{j}=1 \quad$ (baseline) & .43 & .24 & 0 & 0 \\
\hline$g_{m}^{j}, g_{i m}^{j}=.75$ & .57 & .42 & .26 & 0 \\
\hline$g_{m}^{j}, g_{i m}^{j}=.50$ & .71 & .62 & .52 & .15 \\
\hline
\end{tabular}

ii. Effect of income disparity on optimal Medicaid subsidy rate

\begin{tabular}{|l|l|l|l|l|}
\hline \hline Income disparity between high and low productivity & \multicolumn{4}{|l|}{ optimal Medicaid subsidy rate $(\eta)$} \\
\cline { 2 - 5 } workers $\left(\phi_{1}-\phi_{2}\right)$ & $\lambda=1$ & $\lambda=5$ & $\lambda=10$ & $\lambda=100$ \\
\hline$\phi_{1}-\phi_{2}=1 \quad$ (baseline) & .43 & .24 & 0 & 0 \\
\hline$\phi_{1}-\phi_{2}=5$ & .79 & .72 & .66 & .44 \\
\hline \hline
\end{tabular}

iii. Effect of variation in welfare weights of the poor on optimal Medicaid subsidy rate

\begin{tabular}{|l|l|l|l|l|}
\hline \hline Welfare weight on the poor $\left(\omega_{2}\right)$ & \multicolumn{4}{l|}{ optimal Medicaid subsidy rate $(\eta)$} \\
\cline { 2 - 5 } & $\lambda=1$ & $\lambda=5$ & $\lambda=10$ & $\lambda=100$ \\
\hline$\omega_{2}=.5$ & 0 & 0 & 0 & 0 \\
\hline$\omega_{2}=1 \quad$ (baseline) & .43 & .24 & 0 & 0 \\
\hline$\omega_{2}=3$ & .73 & .62 & .53 & .17 \\
\hline \hline $\begin{array}{l}* * \text { These results are for the baseline variation (variation 5) but the qualitative results also apply to variation 2 and are } \\
\text { quantitatively similar. }\end{array}$
\end{tabular}


Table VII. Optimal Medicare subsidy rates $\left(\sigma^{l}, \sigma^{2}\right)$ with means-tested benefits*

\begin{tabular}{|l|l|l|l|}
\hline$\lambda=1$ & $\lambda=5$ & $\lambda=10$ & $\lambda=100$ \\
\hline$\sigma^{l}=.01$ & $\sigma^{l}=.48$ & $\sigma^{l}=.60$ & $\sigma^{l}=.70$ \\
$\sigma^{2}=.42$ & $\sigma^{2}=.76$ & $\sigma^{2}=.81$ & $\sigma^{2}=.86$ \\
\hline \hline
\end{tabular}


Table VIII. Progressive tax rates $\left(\tau^{l}, \tau^{2}\right)$ for a given Medicare subsidy rate (for all $\lambda$ )*

\begin{tabular}{|l|l|l|l|}
\hline \hline$\sigma=.25$ & $\sigma=.45$ & $\sigma=.65$ & $\sigma=.85$ \\
\hline$\tau^{1}=.0354287$ & $\tau^{1}=.0687234$ & $\tau^{1}=.129612$ & $\tau^{1}=.326462$ \\
$\tau^{2}=.001$ & $\tau^{2}=.001$ & $\tau^{2}=.001$ & $\tau^{2}=.001$ \\
\hline \hline
\end{tabular}

